\title{
Effect of Cosolvent in a Nucleophilic Substitution Reaction Using Organoclay in Triphase Catalytic System
}

\author{
Nahid Shabestary*, Cynthia M. Chapple, Derek T. Rensing, Thao T. Doan, Sadegh Khazaeli, \\ Michael J. Sabo, Andrew D. Beach \\ Department of Chemistry, Southern Illinois University Edwardsville, Edwardsville, IL, USA \\ Email: "nshabes@siue.edu
}

Received 26 June 2015; accepted 23 July 2015; published 28 July 2015

Copyright (C) 2015 by authors and Scientific Research Publishing Inc.

This work is licensed under the Creative Commons Attribution International License (CC BY).

http://creativecommons.org/licenses/by/4.0/

(c) (i) Open Access

\begin{abstract}
A remarkable rate enhancement technique has been devised for a typical nucleophilic displacement reaction by using triphase catalytic materials based on tetraoctylammonium exchange forms of hectorite clay. Pseudo-first order rate constants $\left(k_{o b s}\right)$ for the conversion of 1-bromobutane to the corresponding chloride under triphase conditions using the clay catalyst in the presence of various polar cosolvents have been observed. The results here have shown that the addition of a cosolvent increases the catalytic activity of the triphase system by several fold. In addition, the results have demonstrated that each cosolvent has a unique concentration for achieving an optimum reaction rate.
\end{abstract}

Keywords

Triphase Catalysis, Cosolvent, Organoclay, Nucleophilic Displacement Reaction

\section{Introduction}

Recently, triphase catalysis (TC) has been introduced as a unique type of heterogeneous catalysis in which the catalyst and each of a pair of reactants are located in different phases [1]-[7]. The third phase (catalyst) is generally a solid phase, such as synthetic polymers or clay minerals and various oxides. In a triphase system (Figure 1), the reactants from two immiscible liquid phases (usually water and organic solvent, such as toluene) are transferred to the solid interface where they react and make product.

Based on this type of heterogeneous catalysis, numerous synthetic routes have been developed for aqueous-

"Corresponding author.

How to cite this paper: Shabestary, N., Chapple, C.M., Rensing, D.T., Doan, T.T., Khazaeli, S., Sabo, M.J. and Beach, A.D. (2015) Effect of Cosolvent in a Nucleophilic Substitution Reaction Using Organoclay in Triphase Catalytic System. Modern Research in Catalysis, 4, 78-85. http://dx.doi.org/10.4236/mrc.2015.43010 


\section{TRIPHASE CATALYTIC SYSTEM}

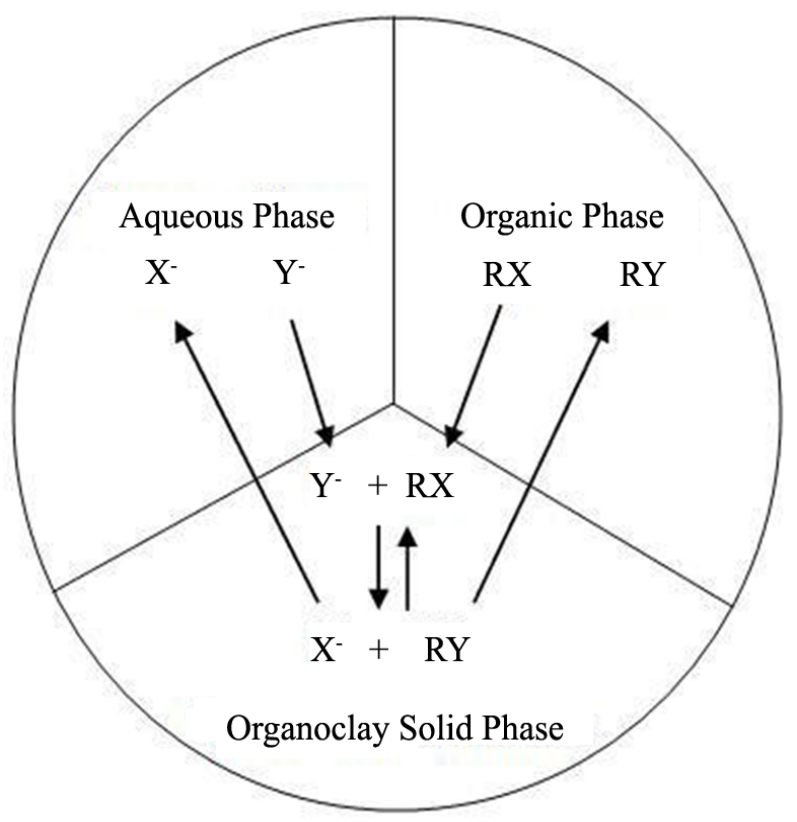

Figure 1. Schematic representation of triphase catalytic system.

organic phase reactions by using a solid phase that supports the catalyst [8]-[11]. Triphase catalysis greatly facilitates the recovery of the catalyst via simple filtration or centrifugation and therefore shows considerable potential for commercial application. As such, more pure product recovery, easier catalyst recycling, and more environmentally benign operation are among advantages of this catalytic system. Several commercially available ion-exchange resins such as Dowex resins containing quaternary ammonium and phosphonium groups have been studied as triphase catalysts [10] [12]. Also, commercially available modified layered clay minerals like Clayton ${ }^{\circledR}$ clays (organoclays) have been intensively studied for various organic syntheses under triphase conditions [11].

The polymer supported triphase catalysts have not yet found industrial applications due to their high cost and stability problems. Other solid supports such as oxides, zeolites and clays have also been explored by various investigators [13]-[18]. However, low catalytic reactivity and in some cases thermal stability problems still remain to be answered. As such, there is a great need for improved triphase catalytic systems to overcome the aforementioned disadvantages.

We wish to report here a promising and remarkable rate enhancement technique for a typical nucleophilic displacement reaction using triphase catalytic materials based on tetraoctylammonium exchange forms of a 2:1 layered silicate clay (hectorite clay from smectite clay family). The cation exchange reaction (clay intercalation reaction) may be represented as follows:

$$
\text { Hectorite clay }+ \text { Onium Salt } \rightarrow[\text { Hectorite clay }]\left[(\text { Onium Head Cation })^{+}\right]\left[\mathrm{X}^{-}\right]
$$

The type of organoclay catalyst used here is efficient, stable, and recyclable and can be used for a variety of organic syntheses [11] [18]. The organic phase contains the substrate (i.e. n-butyl bromide), and the nucleophilic reagent (i.e. $\mathrm{Cl}^{-}$) plus a polar cosolvent are in the aqueous phase, as shown below.

$$
\mathrm{n} \text {-butBr( org })+\mathrm{Cl}^{-}(\mathrm{aq}) \stackrel{\text { iOnium-clay ntercalates }}{\longrightarrow} \mathrm{n}-\mathrm{butCl}(\mathrm{org})+\mathrm{Br}^{-} \text {(aq) }
$$

We have used several polar cosolvents under triphase conditions to increase the rate of the nucleophilic displacement reaction. The use of effective polar cosolvents has been demonstrated in different catalytic systems to promote nucleophilic displacement reactions [19]-[21]. In the present study, we have demonstrated a significant reaction rate enhancement through application of various polar cosolvents in organoclay triphase catalytic system. 


\section{Experimental Procedure and Analysis}

\subsection{Chemicals and Instruments}

All the chemical reagents and solvents were purchased from Aldrich Chemical Co. and used with no further purification. Sodium-rich hectorite clay with a particle size of $<2 \mu \mathrm{m}$ was purchased in pre-centrifuged and spraydried form from the Source Clay Repository, Purdue University. The idealized anhydrous unit-cell formula of hectorite clay is $\mathrm{Na}_{0.67}\left[\mathrm{Mg}_{5.33} \mathrm{Li}_{0.67}\right]\left(\mathrm{Si}_{8.0}\right) \mathrm{O}_{20}(\mathrm{OH}, \mathrm{F})_{4}$ with an experimentally determined cation exchange capacity of $73 \mathrm{meq} / 100 \mathrm{~g}$ of air-dried clay. The clay was purified by removing carbonates using an acetate buffer ( $\mathrm{pH}$ of 5) solution and eliminating non-lattice iron oxides by employing sodium hydrosulfate based on a literature procedure [22].

A Rigaku Miniflex X-ray Diffractometer with a copper x-ray source $\left(\mathrm{K}_{\alpha}=1.54056 \AA\right)$ was used to determine the basal spacing of the clay intercalates. A Perkin Elmer Clarus 500 Gas Chromatograph (GC) equipped with a flame ionization detector and a $20 \mathrm{~m} \times 0.18 \mathrm{~mm}$ Elite- 5 capillary column were used for the kinetics analysis.

\subsection{Hectorite Clay Intercalation Reaction}

An aliquot of $1 \%$ aqueous suspension of hectorite clay was added to an aliquot of aqueous solution of tetraoctylammonium bromide surfactant with a concentration twice that of the clay cation exchange capacity (CEC) to ensure that all the interlayer sodium cations were replaced by tetraoctylammonium ions. The solution was stirred overnight at $50^{\circ} \mathrm{C}$ until the exchange reaction was completed (verified by constancy of the X-ray diffraction pattern). The organically-modified clay (organoclay) was centrifuged and washed with ethanol and water a few times to remove excess tetraoctylammonium salt. The clay intercalates were then re-suspended in water and washed until free of halide ion as tested by an $\mathrm{AgNO}_{3}$ solution. The products were then collected by centrifugation and freeze-dried before storage in a desiccator. X-ray powder diffraction (XRD) analysis was performed to determine the basal spacing of the intercalate. The basal spacing, $\mathrm{d}$ of the intercalated clays were analyzed using Bragg's equation $(\mathrm{n} \lambda=2 \mathrm{~d} \sin \theta)$.

\subsection{Triphase Catalytic Reaction}

The nucleophilic displacement reaction was conducted in a 50-mL culture tube fitted with a Teflon-lined screw cap and magnetic stirrer using procedure detailed below. To the culture tube was added $0.100 \mathrm{~g}$ of freeze dried clay intercalate catalyst, an aliquot of $3 \mathrm{~mL} 3.3 \mathrm{M} \mathrm{NaCl}$ solution, and $2 \mathrm{~mL}$ toluene containing $1 \mathrm{mmol}$ butyl bromide mixed with an appropriate cosolvent solution. The tube was sealed and stirred in an $80 \pm 1^{\circ} \mathrm{C}$ oil bath. Aliquots of $1 \mu \mathrm{L}$ organic solution were withdrawn at 30 minute intervals for $\mathrm{GC}$ analysis to measure the extent of the displacement reaction. Rates of reaction were monitored by following the disappearance of the starting n-butyl bromide from the organic phase using gas liquid chromatography.

For sampling, the tube was removed from the oil bath, quickly cooled by ice water to about $10^{\circ} \mathrm{C}$. After cooling, the tube was opened for sampling via a small syringe and resealed and returned to the bath. The value of $k_{o b s}$ was calculated by plotting $\ln \left\{[\mathrm{n} \text {-butyl bromide }]_{\mathrm{t}} /[\mathrm{n} \text {-butyl bromide }]_{\mathrm{t}=0}\right\}$ vs. the time of reaction. The rate law expression used to calculate the $k_{o b s}$ is given below:

$$
\begin{gathered}
\mathrm{CH}_{3}\left(\mathrm{CH}_{2}\right)_{3}-\mathrm{Br}+\mathrm{Cl}^{-} \rightarrow \mathrm{CH}_{3}\left(\mathrm{CH}_{2}\right)_{3}-\mathrm{Cl}+\mathrm{Br}^{-} \\
\text {Rate }=-\mathrm{d}\left[\mathrm{CH}_{3}\left(\mathrm{CH}_{2}\right)_{3}-\mathrm{Br}\right] / \mathrm{d} t=k\left[\mathrm{Cl}^{-1}\right]\left[\mathrm{CH}_{3}\left(\mathrm{CH}_{2}\right)_{3}-\mathrm{Br}\right]
\end{gathered}
$$

At a high concentration of $\mathrm{NaCl}$ relative to $\mathrm{CH}_{3}\left(\mathrm{CH}_{2}\right)_{3}-\mathrm{Br}$ the equation can be written as:

$$
\begin{gathered}
\text { Rate }=-\mathrm{d}\left[\mathrm{CH}_{3}\left(\mathrm{CH}_{2}\right)_{3}-\mathrm{Br}\right] / \mathrm{d} t=k_{o b s}\left[\mathrm{CH}_{3}\left(\mathrm{CH}_{2}\right)_{3}-\mathrm{Br}\right] \text { or } \\
\ln \left\{\left[\mathrm{CH}_{3}\left(\mathrm{CH}_{2}\right)_{3}-\mathrm{Br}\right]_{t} /\left[\mathrm{CH}_{3}\left(\mathrm{CH}_{2}\right)_{3}-\mathrm{Br}\right]_{t=0}\right\}=-k_{o b s}
\end{gathered}
$$

Note: For recyclability testing, the clay intercalates were filtered and washed with $10 \mathrm{~mL}$ ethanol followed by $10 \mathrm{~mL}$ deionized water prior to reuse. The reproducibility for the $k_{o b s}$ was within $\pm 4 \%$.

\section{Results and Discussion}

Our results on the effect of various polar cosolvents on the triphase reaction kinetics are summarized in Table 1. 
Table 1. Pseudo first order rate constants (at $80 \pm 1 \%{ }^{\circ} \mathrm{C}$ ) for conversion of n-butyl bromide to n-butyl chloride in the presence of an organo clay catalyst under triphase catalytic conditions. ${ }^{\text {a }}$

\begin{tabular}{|c|c|c|c|}
\hline Reaction No. & Cosolvent & \% Cosolvent & $k_{o b s}\left(\mathrm{~h}^{-1}\right)$ \\
\hline 1 & In the absence of cosolvent & 0 & $0.17 \pm 0.02$ \\
\hline 2 & Ethylene Glycol (EG) & 2 & $0.32 \pm 0.03$ \\
\hline 3 & Ethylene Glycol (EG) & 5 & $0.53 \pm 0.02$ \\
\hline 4 & Ethylene Glycol (EG) & 10 & $0.50 \pm 0.04$ \\
\hline 5 & Ethylene Glycol (EG) & 20 & $0.48 \pm 0.04$ \\
\hline 6 & Dimethylsulfoxide (DMSO) & 2 & $0.41 \pm 0.04$ \\
\hline 7 & Dimethylsulfoxide (DMSO) & 5 & $0.69 \pm 0.03$ \\
\hline 8 & Dimethylsulfoxide (DMSO) & 10 & $0.82 \pm 0.07$ \\
\hline 9 & Dimethylsulfoxide (DMSO) & 20 & $0.73 \pm 0.06$ \\
\hline 10 & Acetonitrile (AN) & 2 & $0.29 \pm 0.03$ \\
\hline 11 & Acetonitrile (AN) & 5 & $0.54 \pm 0.03$ \\
\hline 12 & Acetonitrile (AN) & 10 & $0.46 \pm 0.02$ \\
\hline 13 & Dimethylformamide (DMF) & 2 & $0.31 \pm 0.05$ \\
\hline 14 & Dimethylformamide (DMF) & 5 & $0.57 \pm 0.05$ \\
\hline 15 & Dimethylformamide (DMF) & 10 & $0.74 \pm 0.05$ \\
\hline 16 & Dimethylformamide (DMF) & 20 & $0.87 \pm 0.07$ \\
\hline 17 & Dimethylformamide (DMF) & 30 & $0.75 \pm 0.04$ \\
\hline
\end{tabular}

${ }^{a}$ The triphase reaction mixture here consists of freeze dried intercalated hectorite clay, aqueous solution containing $\mathrm{NaCl}$, toluene containing substrate (n-butyl bromide). In each experiment an appropriate amount of cosolvent is used and the amount specified in the table is weight\% based on the aqueous phase that being used (see experimental section for more details). In reaction number 1, only toluene is used as organic phase without presence of a cosolvent. The results have shown that the addition of the cosolvent above increases the catalytic activity of the triphase system by several folds in comparison to the reaction that has no cosolvent.

The data confirm the pseudo first order rate law for the conversion of 1-bromobutane to 1-chlorobutane under these triphase conditions. Here, the tetraoctyl ammonium ion exchange form of hectorite clay (with cation exchange capacity of 73 meq/100g clay) has been used as the triphase catalyst. The intercalation reaction of tetraoctyl ammonium bromide salt with hectorite clay suspension has been verified by XRD. The XRD pattern for the intercalated hectorite vs. pure hectorite is shown in Figure 2 and Figure 3 where a basal spacing of $22 \AA$ is observed.

In addition, the catalytic activity varies with the amount of cosolvent used and appears to approach a maximum rate constant at a certain concentration of cosolvent (Figure 4). Since the cosolvents here are partitioning almost entirely in the aqueous phase, it may be argued that the addition of cosolvent is reducing the nucleophile concentration in the aqueous phase and therefore affecting the rate of reaction. For that reason and also to make sure that reaction rate becomes independent from the nucleophile, we purposely keep the nucleophile concentration in the aqueous phase higher by an order of magnitude than the substrate concentration in the organic phase to nullify this effect.

Also, it is interesting to note that once the onium cations are intercalated, their exchange with sodium ions in the aqueous layer is not favored, due to a great affinity that clay exhibits for this kind of catalyst. Thus, this phenomenon prohibits biphase catalytic reactions within the solution, since little or no leaching of quaternary onium cations out of the clay intercalates occurs despite the high concentration of sodium ion within the reaction mixture. The solid catalyst has been recycled for five times after being washed with ethanol and distilled water, and no significant loss of catalytic activity $(<5 \%)$ was observed. We also observed no significant catalytic activity after removing the solid catalyst (hectorite intercalate) from the reaction mixture by filtration. This suggests 


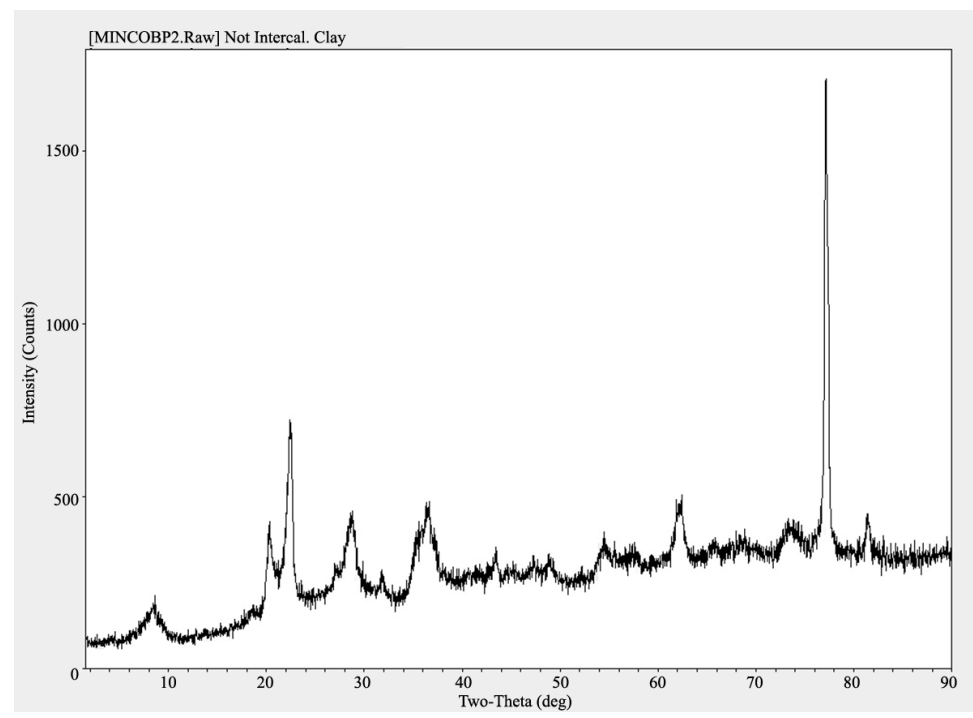

Figure 2.The X-Ray diffraction pattern of pure natural hectorite clay.

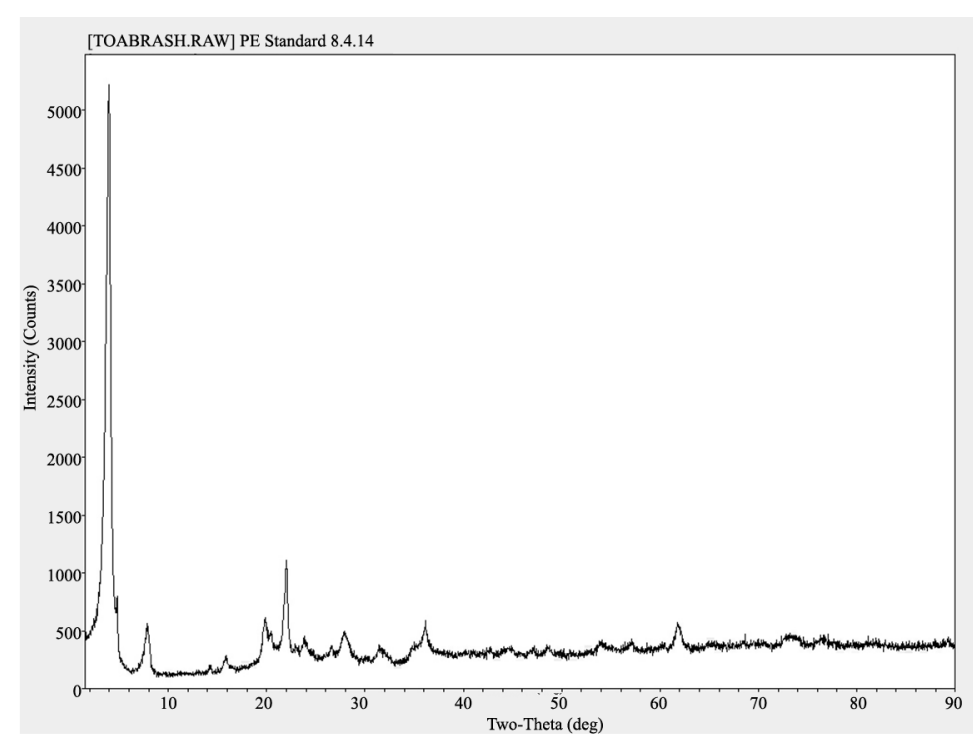

Figure 3. The X-Ray diffraction pattern of $\left(\mathrm{C}_{8} \mathrm{H}_{17}\right)_{4} \mathrm{~N}^{+}$hectorite clay intercalate.

that tetraoctylammonium surfactant is not desorbing from the hectorite clay surface under triphase catalytic reactions and the hectorite intercalate catalyst is quite stable and can be recycled.

Lin and Pinnavaia [18] have argued that organoclays can form thin, membrane-like assemblies of platelets at the liquid-liquid interface of an oil/water type of emulsion, and reagents in emulsified liquid phases are readily transferred to the interface of clay assemblies for facile reaction. We observed that hectorite intercalate emulsions were broken with low-speed centrifugation ( $<2000 \mathrm{RPM})$ and sometimes with long term storage (about 2 weeks). This property allows efficient separation of catalyst from product. However, pure hectorite is unable to emulsify in the triphase system and as a result no catalytic activity was observed with the non-intercalated clay. In addition, we have used the cosolvents in a biphase reaction in the absence of solid phase using the same catalyst (tetraoctylammonium bromide). No significant enhancement in catalytic activity was observed by adding $5 \%$ cosolvent to the reaction mixture. However, increasing the cosolvent concentration beyond $5 \%$ has decreased the catalytic activity by a few folds (this is contrary to the triphase system). It appears that adding cosolvent to a biphase system somehow reduces the organophilicity of the catalyst and hence reduces the reaction rate. 


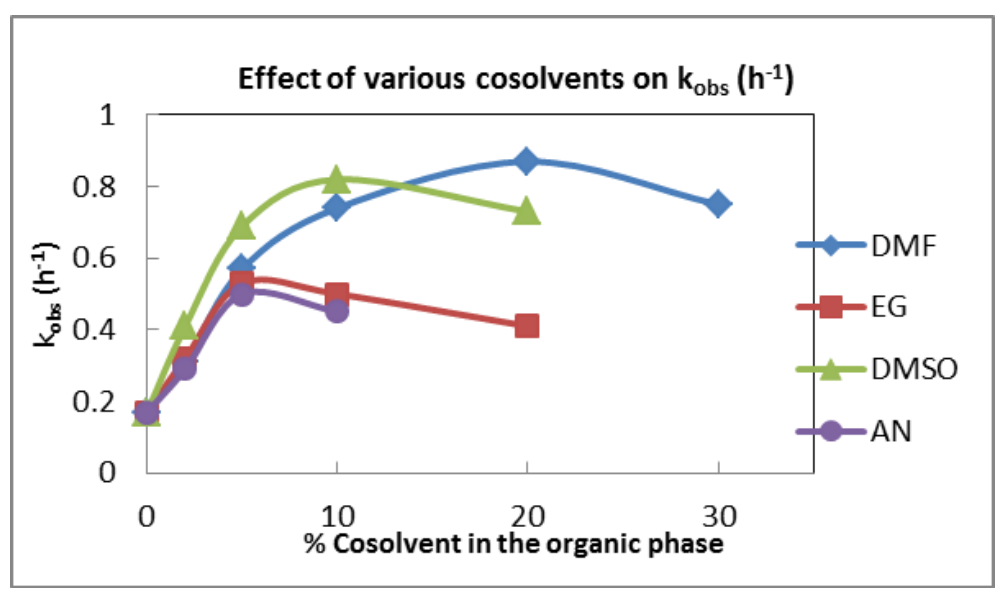

Figure 4. Effect of cosolvent concentration on the rate constant.

Under triphase reaction conditions, it is believed that the addition of cosolvent affects the state of the clay emulsion system. Thus, at a certain concentration of cosolvent, the diffusion and interfacial surfaces of both the aqueous and organic phases within the solid support is at a maximum. Perhaps excessive amount of cosolvent creates a meta-stable solution that promotes demulsification rather than the emulsification enhancement of the system which is necessary to increase interfacial surfaces available for reaction [11]. Our understanding of the mechanism, characteristics, and quantitative measurements of organoclay emulsion formation under the triphase catalytic system at this point is rudimentary. Here, the mechanism is more complicated than traditional heterogeneous supported catalysis, due to the fact that the system involves not only diffusion of a single liquid or gas phase into the solid phase, but rather requires the diffusion of two liquid phases (organic and aqueous) to the surface and pores of the solid phases. Several mechanisms have been proposed by various investigators [23]-[27] for triphase catalysis using polymers as the solid phase; however, none have been completely verified. Little or no literature is available on the mechanism of triphase catalysis using an organoclay as the solid phase. It is possible that at certain concentrations of cosolvent when the reaction rate is at the maximum, there is a fine hydrophilic-lipophilic balance to ensure adequate collisions of droplets of the organic (or aqueous) phase with organoclay particles dispersed in a continuous aqueous (or organic) phase. Therefore, the choice of a proper solvent or cosolvent and their concentration are critical to the catalytic activity of the clay-supported triphase system.

It is interesting that the naturally occurring alkali and alkaline earth cations within the clay can be replaced by almost any cation, such as the quaternary onium cations, $\mathrm{Q}^{+}$, and that the cation exchange in this type of clay is relatively rapid. Thus, modified smectite clays with $\mathrm{Q}^{+}$intercalated between the layers make very successful triphase catalysts [26]. It is remarkable that this kind of organo-complex clay has a great affinity towards water as well as organic reagents. As a result, this unique characteristic of organo-complex smectite clay that combines the hydrophilicity of the aqueous media with the hydrophobicity of the organic environment makes it attractive to function as a triphase catalyst especially in the presence of a cosolvent.

Aside from the amphiphilic property of quaternary ammonium ion clay intercalates, they also have the ability to make a stable three-phase emulsion under triphase catalytic conditions [11] and can serve as an aid rather than an encumbrance in a triphase catalytic reaction. Amphiphilicity and emulsibility of the clay intercalates are two important and attractive characteristics not only for nucleophilic displacement reactions, but also for other important organic synthesis under triphase catalytic conditions.

It appears that quaternary onium ion hectorite intercalates have a great tendency for emulsification in the presence of water and an organic solvent such as toluene. The emulsification facilitated by the clay intercalates helps bring the nucleophile from the aqueous phase into contact with the substrate that is contained in the organic phase. It is anticipated that a higher degree of emulsification leads to higher catalytic activity. The degree of emulsification and its stability depend on various factors such as the shape of the onium cation and the characteristics of the intercalates [18] [27]. We would like to claim that in our system, the cosolvent is another strong factor in improving the stability of the clay emulsification system, which leads to a significant enhancement in catalytic activity. 


\section{Conclusion}

A significant catalytic activity enhancement has been observed in a triphase catalytic system by using a cosolvent. It is observed that the catalytic activities are varied with the amount and type of cosolvent. However, an increase in the catalytic activity approaches a maximum rate constant at a certain concentration of cosolvent where adding more cosolvent subsequently decreases the activity. It appears that at a certain concentration of cosolvent, the diffusion and interfacial surfaces of both the aqueous and organic phases within the solid support are at a maximum. At this maximum, the cosolvent is a strong factor in improving the stability of the clay emulsion formation where the catalytic activity increases by several folds. Due to the vast selection of cosolvent, there is ample potential for exploring higher catalytic activity in this type of triphase system.

\section{Acknowledgements}

We would like to thank the donors of the American Chemical Society Petroleum Research Fund for support of this research (ACS PRF\# 43890-B5), the Division of Undergraduate Education, DUE-CCLI, at the National Science Foundation (DUE-0410642) for support of the X-ray powder diffraction instrument used in this research, and the SIUE Undergraduate Research and Creative Activities Program, URCA.

\section{References}

[1] Regen, S.L. (1979) Dreiphasen-Katalyse. Angewandte Chemie, 91, 464-472. http://dx.doi.org/10.1002/ange.19790910605

[2] Regen, S.L. (1975) Triphase Catalysis. Journal of the American Chemical Society, 97, 5956-5957. http://dx.doi.org/10.1021/ja00853a074

[3] Shabestary, N., Rensing, D.T., Reed, D.N., Austiff, A.F. and Cox, M.D. (2014) Triphase Catalysis Based on Gemini Surfactant-Clay Intercalates. Modern Research in Catalysis, 3, 26-34. http://dx.doi.org/10.4236/mrc.2014.32005

[4] Murugan, E. and Gopinath, P. (2009) Triphase Catalytic Activity of a New Insoluble Multi-Site Phase Transfer Catalyst in C-alkylation of Dihydrocarvone-A Kinetic Study. Journal of Molecular Catalysis A: Chemical, 309, 12-20. http://dx.doi.org/10.1016/j.molcata.2009.04.009

[5] Ragaini, V., Verzella, G., Ghignone, A. and Colombo, G. (1986) Fixed-Bed Reactors for Phase-Transfer Catalysis. A Study of a Liquid-Liquid-Solid Reaction. Industrial Engineering Chemistry Process Design and Development, 25, 878885. http://dx.doi.org/10.1021/i200035a007

[6] Dutta, N.N., Borthakur, S. and Patil, G.S. (1992) Triphase Catalysis for Recovery of Phenol from an Aqueous Alkaline Stream. Industrial Engineering Chemistry Research, 31, 2727-2731. http://dx.doi.org/10.1021/ie00012a015

[7] Dutta, N.N. and Pangarkur, V.G. (1994) Liquid-Liquid-Solid Reactions: Esterification of Phenol with Benzoyl Chloride Using a Polymer-Supported Phase Transfer Catalyst. Reactive Polymers, 22, 9-17. http://dx.doi.org/10.1016/0923-1137(94)90092-2

[8] Yadav, G.D. and Naik, S.S. (2000) Clay-Supported Liquid-Liquid-Solid Phase Transfer Catalysis: Synthesis of Benzoic Anhydride. Organic Process Research \& Development, 4, 141-146. http://dx.doi.org/10.1021/op990087c

[9] Danao, S.P., Thorat, R.T. and Nageshwar, G.D. (2005) Kinetics of Oxidation of Phenethyl Alcohol by Triphase Catalysis. Indian Chemical Engineer, 47, 156-160.

[10] Dutta, N.N., Ghosh, A.C. and Mathur, R.K. (1997) Rate-Limiting. In: Halpern, M.E., Ed., American Chemical Society Publication, Symposium Series 659, Chapter 20, American Chemical Society, Washington DC, 261-276.

[11] Pinnavaia, T.J. (1992) Organoclay Triphase Catalysts. U.S. Patent 5,099,054.

[12] Regen, S.L. and Besse, J.J. (1979) Liquid-Solid-Liquid Triphase Catalysis. Consideration of the Rate-Limiting Step, Role of Stirring, and Catalyst Efficiency for Simple Nucleophilic Displacement. Journal of the American Chemical Society, 101, 4059-4063. http://dx.doi.org/10.1021/ja00509a008

[13] Venturello, P., Tundo, P. and Angeletti, E. (1982) Anion-Exchange Properties of Ammonium Salts Immobilized on Silica Gel. Journal of the American Chemical Society, 104, 6547-6551. http://dx.doi.org/10.1021/ja00388a011

[14] Venturello, P., Tundo, P. and Angeletti, E. (1982) Phase-Transfer Catalysts Immobilized and Adsorbed on Alumina and Silica Gel. Journal of the American Chemical Society, 104, 6551-6555. http://dx.doi.org/10.1021/ja00388a012

[15] Cornelis, A., Laszlo, P. and Pennetreau, P. (1983) Some Organic Syntheses with Clay Supported Reagents. Clay Minerals, 18, 437-445. http://dx.doi.org/10.1180/claymin.1983.018.4.09

[16] Kadkhodayan, A. and Pinnavaia, T.J. (1983) Clay Intersalation Compounds for Selective Triphase Catalysis: Reaction 
of Alkyl Bromide with NaCl. Journal of Molecular Catalysis, 21, 109-117. http://dx.doi.org/10.1016/0304-5102(93)80114-A

[17] Cornelis, A. and Laszlo, P. (1982) Clay-Supported Reactions; II. Quaternary Ammonium-Exchanged Montmorillonite as Catalyst in the Phase-Transfer Preparation of Symmetrical Formaldehyde Acetals. Synthesis, 2, 162-163. http://dx.doi.org/10.1055/s-1982-29732

[18] Lin, C.L. and Pinnavaia, T.J. (1991) Organo Clay Assemblies for Triphase Catalysis. Chemistry Materials, 3, $213-215$. http://dx.doi.org/10.1021/cm00014a003

[19] Regen, S.L., Nigam, A. and Besse J. (1978) Triphase Catalysis. Insolubilized Hexamethylphosphoramide as a Solid Solvent. Tetrahedron Letters, 19, 2757-2760. http://dx.doi.org/10.1016/S0040-4039(01)94853-1

[20] Tomoi, M., Ikeda, M. and Kakiuchi, H. (1978) Polymer-Supported Phosphoric Triamides as Catalysts for PhaseTransfer Reactions. Tetrahedron Letters, 19, 3757-3758. http://dx.doi.org/10.1016/S0040-4039(01)95051-8

[21] Regen, S.L., Mehrota, A. and Singh, A. (1981) Poly(acrylamide)-Based Solid-Phase Cosolvents. Journal of Organic Chemistry, 46, 2182-2184. http://dx.doi.org/10.1021/jo00323a045

[22] Mills, J.G. and Zwarich, M.A. (1972) Recognition of Interstratified Clays. Clays and Clay Minerals, 20, 169-174. http://dx.doi.org/10.1346/CCMN.1972.0200309 http://www.clays.org/journal/archive/volume\%2020/20-3-169.pdf

[23] Hradil, J. and Svec, F. (1984) Phase Transfer Catalysis. Polymer Bulletin, 11, 159-164. http://dx.doi.org/10.1007/BF00258023

[24] Telford, S., Schlunt, P. and Chau, P.C. 1986) Mechanism of Polymer-Supported Phase-Transfer Catalysis. Effect of Phase Ratios on Low-Percent Ring Substitution Microporous Polystyrene Resin. Macromolecules, 19, 2435-2439. http://dx.doi.org/10.1021/ma00163a018

[25] Ruckenstein, E. and Hong, L. (1992) Hydrophilic Recognition by Polymer-Supported Phase Transfer Catalysts and Its Effect on Reaction Activity and Selectivity. Journal of Catalysis, 136, 378-391. http://dx.doi.org/10.1016/0021-9517(92)90069-T

[26] Svec, F. (1988) What Is the Real Mechanism of Polymer-Supported Phase-Transfer Catalysis. Pure and Applied Chemistry, 60, 377-386. http://dx.doi.org/10.1351/pac198860030377

[27] Shabestary, N., Khazaeli, S. and Long, N. (2005) Triphase Catalytic Reactions Using Clay Intercalates. International Journal of Science \& Technology (Scientia Iranica), 12, 290-294. http://en.journals.sid.ir/ViewPaper.aspx?ID=35171 